\title{
Removal of Cr(VI) From Electroplating Industry Effluent via Electrochemical Reduction
}

\author{
Shiyou $\mathrm{Li}^{1}$, Zhongqing $\mathrm{Hu}^{1}$, Shuibo Xie ${ }^{1,2}$, Haiyan Liu ${ }^{l}$, Jinxiang Liu ${ }^{1, *}$ \\ ${ }^{1}$ Hunan Provincial Key Laboratory of Pollution Control and Resources Technology, University of \\ South China, Hengyang, Hunan, 421001, P.R. China. \\ ${ }^{2}$ Key Discipline Laboratory for National Defence for Biotechnology in Uranium Mining and \\ Hydrometallurgy, University of South China, Hengyang, Hunan, 421001, P.R. China. \\ *E-mail: liu2000gps@sina.com
}

doi: $10.20964 / 2018.01 .83$

Received: 6 October 2017 / Accepted: 19 November 2017 / Published: 16 December 2017

In the present work, an electrochemical reduction process with iron and titanium electrodes was investigated for hexavalent chromium $(\mathrm{Cr}(\mathrm{VI}))$ removal. The removal of $\mathrm{Cr}(\mathrm{VI})$ and its resulting species was investigated by measuring the efficiency of the electrochemical reduction treatment. For the $\mathrm{Cr}(\mathrm{VI})$ removal, a lower performance was found for the titanium electrode than the iron electrode. Therefore, the resulting $\mathrm{Cr}(\mathrm{VI})$ reduction, which occurred through electrochemical reduction using iron electrodes, was chemical reduction by the anodically generated $\mathrm{Fe}(\mathrm{II})$. Furthermore, the resulting $\mathrm{Cr}(\mathrm{III})$ was efficiently precipitated as $\mathrm{Cr}(\mathrm{OH})_{3}$ and was rapidly removed from solution.

Keywords: Pollution management; Electrode configuration; Industry Effluent; Electrochemical reduction; $\mathrm{Cr}(\mathrm{VI})$ removal

\section{FULL TEXT}

(C) 2018 The Authors. Published by ESG (www.electrochemsci.org). This article is an open access article distributed under the terms and conditions of the Creative Commons Attribution license (http://creativecommons.org/licenses/by/4.0/). 